\title{
Structure of a novel flavin chromophore from Avena coleoptiles, the possible 'blue light' photoreceptor
}

\author{
Sandro GHISLA, Rudi MACK, Gunter BLANKENHORN, Peter HEMMERICH ${ }^{\dagger}$, Eberhard KRIENITZ, and Thomas KUSTER \\ Fakultät für Biologie der Universität Konstanz; Efeka Arzneimittelfabrik GmbH \& Co KG, Hannover; and \\ Medizinisch chemische Abteilung der Universitätskinderklinik Zürich
}

(Received July 28/October 31, 1983) - EJB 830815

A yellow chromophore has been isolated from Avena coleoptiles grown in the dark. It had previously been shown by Zenk [Zenk, M. H. (1967) Z. Pflanzenphysiol. 56, 122-140] to be a flavin of still unidentified structure, and had been suggested to be the "blue light' photoreceptor in this organism. The structure of this flavin (F1-X) has been identified as $5^{\prime}$-malonylriboflavin by a combination of physicochemical techniques, and by its identity with a sample obtained synthetically. The 5'-malonylester linkage is relatively labile towards hydrolysis and photolysis, it isomerizes to an equilibrium mixture containing probably the $4^{\prime}$ isomer. The electronic spectra of $5^{\prime}$-malonylriboflavin (absorption and fluorescence) are practically identical to those of normal riboflavin (vitamin $B_{2}$ ).

Phototropic organisms contain a 'blue light receptor', a pigment, which is responsible for the primary conversion of light into a signal triggering growth towards the light source. This cardinal problem is still poorly understood $[1,2]$. In particular, the chemical identity of the 'blue light receptor', the existence of which can be deduced from phototropic action spectra, has been subject to controversy, and speculation [2]. In some organisms, e.g. in Avena coleoptiles, a yellow chromophore has been found in relatively high concentration, to which the role of a primary 'blue light receptor' has been ascribed $[3,4]$. This chromophore was called by Zenk F1-X, and was recognised as being a flavin of still unknown chemical structure. Elucidation of the chromophores structure is considered to be a problem of primary importance, and we share Zenk's opinion, which was put forward in the publication originally describing the discovery of F1-X [3]: 'A primary requirement for the understanding of each photobiological process is the unequivocal identification of the receptor pigment involved. Without such an identification it is difficult to make deductions on the reaction mechanisms at molecular level.' Based on Zenk's report describing this unstable chromophore, and his suggestion [4] that it might constitute a riboflavin ester, we set out to determine its structure.

\section{MATERIALS AND METHODS}

\section{Growth, harvesting, and extraction of Avena coleoptiles}

The purification procedure is outlined in Scheme 1. Oat seeds type 'Arnold' of EG-Norm quality (certificate no. D/KA 801906). The seeds were purchased from Raiffeisen Zentralgenossenschaft G.m.b.H. They were spread evenly at $1 \mathrm{~kg} / \mathrm{m}^{2}$ on DAB 7 cellulose sheets (manufacturer: Michallik-Mühlacker). The growth substrate was humidified with deionised water, the ambient humidity was kept at $\approx 90 \%$, and the temperature at $20-22^{\circ} \mathrm{C}$. After sowing the oats, all manipula-

${ }^{+}$Deceased on October 3, 1981.

Abbreviations. F1-X, 5'-malonylriboflavin; HPLC, high-pressure liquid chromatography. tions were carried out in $\operatorname{dim}$ red light $(\lambda>600 \mathrm{~nm})$. The coleoptiles from $0.6 \mathrm{~kg}$ oats were allowed to grow to a length of $3-4 \mathrm{~cm}$ (in cycles of five days), harvested by cutting with a sharp knife and immediately homogenised at $0-4^{\circ} \mathrm{C}$ in a Waring blender for $3 \mathrm{~min}$, at high speed, and in a minimal volume $10 \mathrm{mM}$ phosphate buffer $\mathrm{pH} 7$. The homogenate was centrifuged for $20 \mathrm{~min}$ at $48000 \times \mathrm{g}$. The clear supernatant contains $\approx 0.17 \mu \mathrm{mol}$ (total) flavin, as judged by fluorimetric analysis. For this determination a sample was diluted $1: 10(\mathrm{v} / \mathrm{v})$ in $\mathrm{EtOH}$ and was measured against a riboflavin standard. Excitation: $445 \mathrm{~nm}$, emission: $520 \mathrm{~nm}$.

\section{Preparation of the affinity matrix for riboflavin binding protein}

Riboflavin binding protein was isolated from egg white by the method of Blankenhorn et al. [5]. For the coupling ( $960 \mathrm{mg}$, $30 \mu \mathrm{mol}$ protein, and $100 \mathrm{ml}$ Sepharose-4B) essentially the procedure of Pharmacia as described by Mayhew and Strating for the immobilisation of flavodoxin [6] was followed, the reaction being conducted in $0.1 \mathrm{M}$ sodium pyrophosphate buffer, $\mathrm{pH} 8.5$ at $2^{\circ} \mathrm{C}$ for $14 \mathrm{~h}$. The capacity of the column was tested by titration with riboflavin in $10 \mathrm{mM}$ phosphate buffer $\mathrm{pH} 7.0$ and was found to be $150 \mathrm{nmol}$ riboflavin $/ \mathrm{ml}$ gel, yielding a $50 \%$ binding capacity. Such an affinity column has proven stable for over 2 years in our hands, when used weekly for the isolation of flavins.

\section{Chemical synthesis of 5'-malonylriboflavin}

Riboflavin $1.9 \mathrm{~g}(\approx 5 \mathrm{mmol})$ was suspended in $15 \mathrm{ml}$ freshly distilled, hot, dry dimethylformamide in a round bottom flask. After cooling to $\approx 25^{\circ} \mathrm{C}, 530 \mathrm{mg}(5 \mathrm{mmol})$ malonic acid and $5 \mathrm{~g}$ ( $25 \mathrm{mmol}$ ) dicyclohexylcarbodiimide were added in small portions over a period of $\approx 1 \mathrm{~h}$, while the reaction mixture was being stirred, and the temperature kept at $25^{\circ} \mathrm{C}$. Additional dimethylformamide $(\approx 20 \mathrm{ml}$ ) was added in portions during the process to prevent solidification of the mixture. The reaction was allowed to proceed for $72 \mathrm{~h}$; during this time samples of the reaction mixture were spotted on silicagel thin-layer chromatography plates at regular intervals and developed in 
butanol/acetic acid/water $(12: 3: 5, \mathrm{v} / \mathrm{v} / \mathrm{v})$; riboflavin, FMN, and natural F1-X from Avena coleoptiles were used as reference. During the 72-h period the gradual increase of intensity of a spot with a $R_{\mathrm{F}}$-value identical to that of natural F1-X, amongst a host of unidentified spots was observed. The reaction was stopped when the relative intensity of the spot with the F1-X-like $R_{\mathrm{F}}$-value had reached an optimal value. The relative concentration of F1-X subsequently decreased.

The reaction mixture was first extensively extracted with diethylether, the resulting material was centrifuged, and the residue extracted with three portions of $50-70 \mathrm{ml}$ of ethyl alcohol. The ethanol solution $(\approx 200 \mathrm{ml})$ was evaporated to $2-3 \mathrm{ml}$, it contains mainly F1-X, and relatively little riboflavin together with a series of not identified riboflavin monomalonyl and polymalonyl esters. To this residue were added $50 \mathrm{ml}$ of $10 \mathrm{mM}$ Tris buffer $\mathrm{pH}$ 7.0. Undissolved solids were separated by centrifugation at $20000 \times g$ for $10 \mathrm{~min}$, and the supernatant was applied to a DEAE-cellulose DE 52 column $(50 \times 90 \mathrm{~mm})$ equilibrated with the same Tris buffer. F1-X was eluted with $10 \mathrm{mM}$ Tris/ $\mathrm{HCl}$ buffer $\mathrm{pH} 7$ in the fractions from $300-500 \mathrm{ml}$ and was identified by thin-layer chromatography. The fractions containing F1-X were pooled, the volume was reduced to $25 \mathrm{ml}$ by flash evaporation and applied to a cellulose (Merck, Avicel) column $(55 \mathrm{~mm} \times 800 \mathrm{~mm})$ equilibrated with distilled water. On this column F1-X (5'-malonylriboflavin) was separated from riboflavin and small amounts of unidentified chromophores by elution with distilled water, the eluate was lyophilized, the $\mathrm{F} 1-\mathrm{X}$ residue was then redissolved in a minimal amount $(<1000 \mu \mathrm{l})$ of ethanol and subjected to final purification by HPLC (RP-18 column) in several runs (cf. Fig. 1). The F1-X fractions obtained were pooled and lyophilized to yield $\approx 25 \mathrm{mg}$ of purest synthetic 5'-malonylriboflavin. $\mathrm{C}_{18} \mathrm{H}_{22} \mathrm{~N}_{4} \mathrm{O}_{9} \cdot 1 \mathrm{H}_{2} \mathrm{O}\left(M_{\mathrm{r}} 456.41\right)$ requires: C $47.36 \%$, H $5.30 \%$, N $12.28 \%$. Found: C $47.34 \%$, H $5.39 \%$, N $11.14 \%$.

Fluorimetric measurements were carried out with a Perkin elmer MPF3 Fluorimeter or with a Yobin Yvon Spectrofluorimeter JY 3D equipped with a computer system (Hewlett Packard 9825A) for correction of excitation and emission spectra. Mass spectroscopic measurements were carried out on a Finnigan 3200 mass spectrometer linked with a Finnigan INCOS 2000 data system either by heated direct insertion $\left(80-300^{\circ} \mathrm{C}\right)$ at an ionisation energy of $50 \mathrm{eV}$, or by gas chromatographic/mass spectroscopic analysis of the hydrolyzed samples. $10 \mu \mathrm{g} \mathrm{Fl-X}$ were treated with $100 \mu \mathrm{l} 0.5 \mathrm{M}$ hydrochloric acid in methanol. After 30 min $1 \mu$ l of the solution was injected. Gas chromatograph: Finnigan 9500; injection temperature: $28^{\circ} \mathrm{C}$; carrier gas: 0.4 bar helium at an inlet split ratio of $1: 5$; temperature program: $5 \mathrm{~min} 80-200^{\circ} \mathrm{C}$ at a rate of $8{ }^{\circ} \mathrm{C} / \mathrm{min}$; column: $20 \mathrm{~m} \times 0.3 \mathrm{~mm}$ (internal diameter) of 1701 glass capillary (Jäggi, Labor für Chromatographie, Trogen, Switzerland); mass spectrometer: electron impact ionization at $50 \mathrm{eV}$; scan range $m / z 50-350$ with a cycle time of $1.5 \mathrm{~s}$. The NMR spectra were recorded with a Bruker $250 \mathrm{MHz}$ instrument. Ultraviolet-visible adsorption spectra were recorded on a Kontron Uvikon 820 double beam instrument at $25^{\circ} \mathrm{C}$. HPLC separation experiments were done with a Kontron system using a $3.9 \times 300 \mathrm{~mm}$ RP-18 column (Waters Bondapak) with a methanol gradient (cf. legend of Fig. 1). Thin-layer chromatography was made using Merck silicagel or cellulose thin-layer plates (cf. also legend to Table 1). The microdetermination of riboflavin was kindly performed by Prof. Dr Bacher (Munich) using the Bacillum casei system [7].

Lumiflavin, riboflavin, tetraacetylriboflavin, and tetraformyl-riboflavin were gifts from Hoffman-La Roche, Basel. Lumiflavin-3-propionesulfonic acid was obtained by alkyla-

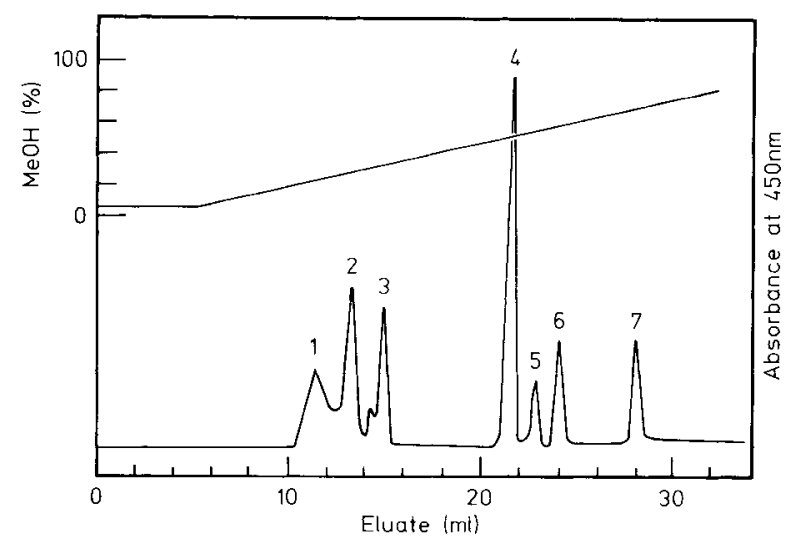

Fig. 1. HPLC elution profile of F1-X (5'-malonylriboflavin), and various natural and synthetic flavin derivatives as comparison, and reference. The samples were applied in a volume of $80 \mu \mathrm{l}$ to a $20^{\circ} \mathrm{C}$ Waters RBP-18 column, and were eluted with the methanol/water gradient shown. (1) FAD; (2) FMN; (3) F1-X; (4) riboflavin; (5) tetraformylriboflavin; (6) lumiflavin; and (7) tetraacetylriboflavin. The peaks were detected by their absorption at $450 \mathrm{~nm}$ or $260 \mathrm{~nm}$. Note the shoulder eluting shortly before 5 -malonylriboflavin, peak 3 ; this is attributed to the presence of the isomeric $4^{\prime}$-malonylriboflavin. When the main peak 3 is collected ad subjected to rechromatography under the same conditions, the same elution profile is obtained as with original F1-X (i.e. main peak + shoulder). Identical behaviour was observed with native, and synthetic F1-X

tion of lumiflavin with propane sulfone in dimethylformamide in the presence of anhydrous $\mathrm{K}_{2} \mathrm{CO}_{3}$ in analogy to the method published earlier [8], and was purified by recrystallisation of the barium salt. FMN and FAD were from Sigma, DE-52 Anion Exchanger microgranular (catalogue no. 4057) was from Whatman.

\section{RESULTS AND DISCUSSION}

\section{Growth of Avena coleoptiles and purification of F1-X}

The growth of Avena coleoptiles was carried out as described in Materials and Methods, care being taken, that light with $\lambda<600 \mathrm{~nm}$ be excluded from the ambient. F1-X was found to be rather unstable due to photodegradation and hydrolysis at early purification stages (hydrolysis to riboflavin), thus all purification procedures were carried out in dim red light and a quick purification procedure (Scheme 1) in particular an early removal of the bulk of contaminating material was mandatory in the development of the purification process.

The crucial improvement of the previous isolation procedure [3] consisted in the use of a high capacity affinity matrix, which is highly selective for riboflavin [5], and which was found to retain also $\mathrm{F} 1-\mathrm{X}$ with sufficient affinity. Its main merit consists in the rapid separation of $F 1-X$ from the bulk of watersoluble contaminants contained in the clear supernatant obtained after centrifugation of the crude extract (cf. Scheme 1). Thus it is possible to isolate quantities of $\mathrm{F} 1-\mathrm{X}$ high enough to perform structural analysis.

The clear supernatant obtained from centrifugation of the coleoptile extract was applied directly to a 'riboflavin binding protein' affinity column (bed volume approx. $100 \mathrm{ml}$, flow rate $6-8 \mathrm{ml} / \mathrm{min}$ ). The column was then washed with distilled water until $A_{280} \mathrm{~nm}<0.05$; riboflavin, $\mathrm{F} 1-\mathrm{X}$ and carotenes were then eluted with $90 \%$ ethanol. The application of a water/ 


$\begin{array}{ll}\text { OAT SEED } & 0.6 \mathrm{~kg} \\ \begin{array}{l}\downarrow \text { germination } \\ \text { COLEOPTILES }\end{array} & 200 \mathrm{~g} \\ \begin{array}{l}\text { flavin extraction } \\ \text { phosphate buffer } \\ \text { pH } 7.0\end{array} & \\ \text { TOTAL FLAVINS } & 70 \mu \mathrm{g} \\ \begin{array}{l}\text { affinity } \\ \text { chromatography }\end{array} & \approx 0.2 \mu \mathrm{mol} \\ \text { RIBOFLAVIN/FLAVIN-X } & \approx 0.17 \mu \mathrm{mol} \\ \begin{array}{l}\text { cellulose } \\ \text { chromatography }\end{array} & 0.1 \mu \mathrm{mol} \\ \text { FLAVIN-X } & \boldsymbol{A}_{265} / A_{445}=3.6 \\ \text { FLAVIN-X } & 0.06 \mu \mathrm{mol}\end{array}$

Scheme 1. Purification of F1-X

Table 1. Thin-layer chromatographic properties of $F 1-X$

The systems were: (A) Merck, cellulose on plastic foil, and $0.5 \%$ ammonium acetate in distilled water; (B) the same plates in pyridine/isopropanol/water $(3: 1: 1, \mathrm{v} / \mathrm{v} / \mathrm{v})$; and (C) $0.2 \mathrm{~mm}$ silicagel on glass plates (Merck) in butanol/acetic acid/water $(12: 3: 5, \mathrm{v} / \mathrm{v} / \mathrm{v})$. The flavin compounds were visualised by their fluorescence (excitation $300-400 \mathrm{~nm}$ ) and expressed in arbitrary units

\begin{tabular}{lllll}
\hline System & F1-X & Riboflavin & FMN & FAD \\
\hline A & 65 & 25 & 80 & 85 \\
B & 55 & 80 & 40 & 20 \\
C & 45 & 55 & 30 & 15 \\
\hline
\end{tabular}

ethanol gradient did not prove practical for this elution. The eluate, $200 \mathrm{ml}$, was reduced to $20 \mathrm{ml}$ by flash evaporation. For the unequivocal identification of F1-X the three chromatographic systems detailed in Table 1 were routinely employed. At this stage $\approx 90 \%$ of the total flavin extracted was recovered, F1-X amounting to about two thirds of the total flavin, as estimated from the fluorescence intensity of thin-layer chromatography compared to that of a riboflavin standard. A substantial amount of carotenes was still present at this stage. These were separated in the next step, in which the concentrated eluate from the affinity chromatography, approx. $20 \mathrm{ml}$, was applied to a $55 \times 800-\mathrm{mm}$ cellulose column equilibrated with water. F1-X was eluted $(2 \mathrm{ml} / \mathrm{min})$ at $450-700 \mathrm{ml}$ of water, while riboflavin was considerably retarded $(2000-2500 \mathrm{ml})$, and most carotenes adhered to the top $2 \mathrm{~cm}$ of the column. For regeneration of such cellulose columns, the yellow (carotene containing) layer was removed mechanically, discarded, and replaced with fresh material. The F1-X obtained was essentially pure on thin-layer chromatograms (cf. Table 1) when visualised by fluorescence emission (excitation $450 \mathrm{~nm}$ ), it had a ratio $A_{265} / A_{445} \approx 3.6$. However, it contained numerous peptidic impurities, which could be removed in the last step, the RP-18 HPLC chromatography with a water/methanol gradient, as described in Material and Methods.

The overall recovery of F1-X was $\approx 70 \%$, the $A_{265} / A_{445}$ $\approx 2.6$, i.e. practically identical to that of pure riboflavin $(=2.68[9])$.

\section{Chemical and physicochemical properties of Fl-X}

The early investigations of Zenk have made it clear that the yellow pigment isolated from Avena coleoptiles contains the

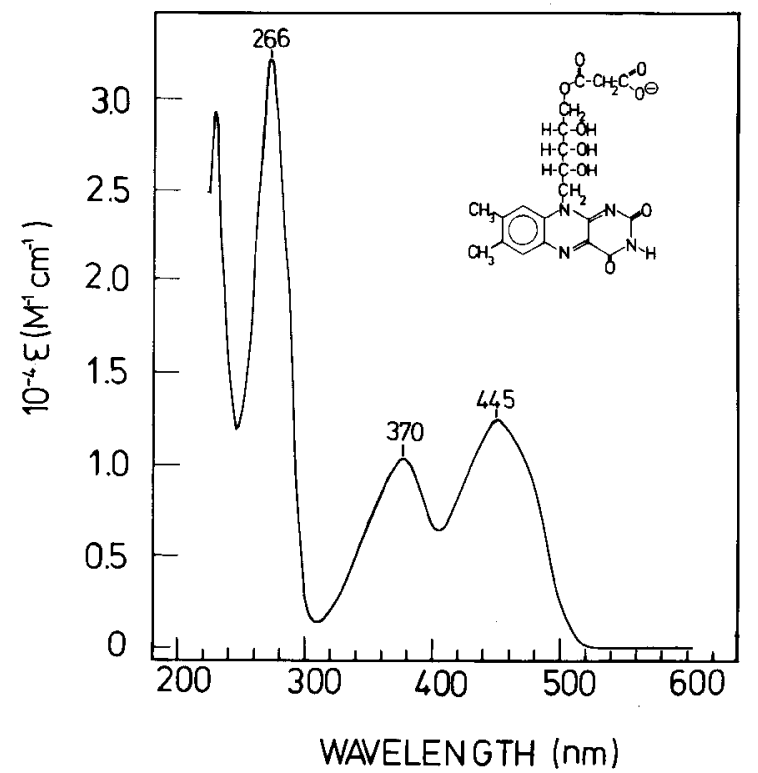

Fig. 2. Ultraviolet and visible absorption spectrum of $F \mathrm{I}-X$. The purest fraction of native F1-X, i.e. 5'malonylriboflavin (see structure insert) obtained from HPLC purification (see text, and Fig. 1), was measured in methanol. The ratio of $A_{265} / A_{445}$, which is indicative of purity, is 2.6. The spectra of native and synthetic F1-X are indistinguishable

isoalloxazine nucleus as chromophore [3]. The latter must be substituted at position 10 with a ribityl residue, as in riboflavin (vitamin $B_{2}$ ), since decay during purification and mild (acidic or basic) hydrolysis converts F1-X to a product which is indistinguishable from riboflavin by chromatographic methods. The facile hydrolysis also indicates that the modifying residue is not linked to the isoalloxazine nucleus directly as in the case of the 6 - or $8 \alpha$-modified flavins [ $10-14]$ but most probably, to the polyhydroxy N10 side chain via an ester-like bond. The ultraviolet spectrum of highly purified F1-X (Fig. 2) is virtually indistinguishable from that of authentic riboflavin. The position of the maxima is identical, the ratio of the maxima and minima, particularly the $A_{265} / A_{445}$ ratio $(=2.6)$, the $\lambda_{\text {max }}$, and the quantum yield of the fluorescence emission also are practically the same as those of riboflavin. At $\mathrm{pH}$ values of 10 and $\approx 0$ the same spectral changes as those of normal flavins, i.c. deprotonation at position $\mathrm{N} 3-\mathrm{H}(\mathrm{p} K \approx 10)[15]$ and protonation at $\mathrm{N} 1(\mathrm{p} K<0)[16]$ are observed.

From this it is evident that the side chain of F1-X must be linked to an aliphatic or an inorganic residue having negligible spectral interaction with the isoalloxazine nucleus. A first clue as to the nature of this residue comes from mobility of F1-X on thin-layer chromatography (Table 1). This indicates that its polarity must be intermediate between that of FMN and of riboflavin itself. The residue also confers a net negative charge to $\mathrm{F} 1-\mathrm{X}$ at neutral $\mathrm{pH}$ as shown by its electrophoretic mobility in comparison to flavins carrying differently charged groups. The HPLC elution diagram (Fig. 1), which shows F1-X eluting shortly after FAD and FMN but well before riboflavin and other less polar flavin derivatives is consistent with this deduction. The group is not an amino acid, as e.g. in the case of the F-420 chromophore where a $5^{\prime}$ linkage to a lactylglutamate residue is present [16], as no ninhydrin-positive residue was found upon hydrolysis and amino acid analysis. From its electrophoretic mobility at different $\mathrm{pH}$ values and in comparison to FMN and lumiflavin-3-propanesulfonic acid the 
presence of a group with a $\mathrm{p} K 3.1$ (Fig. 3) was deduced. This set of data clearly pointed to the presence of a carboxylic acid residue the $\mathrm{p} K$ of which is influenced by the presence of specific substituents. All attempts to obtain information on the molecular weight of F1-X by various mass spectrometric techniques failed, no molecular peak could be obtained, and the fragmentation pattern was significantly different from that of e.g. riboflavin.

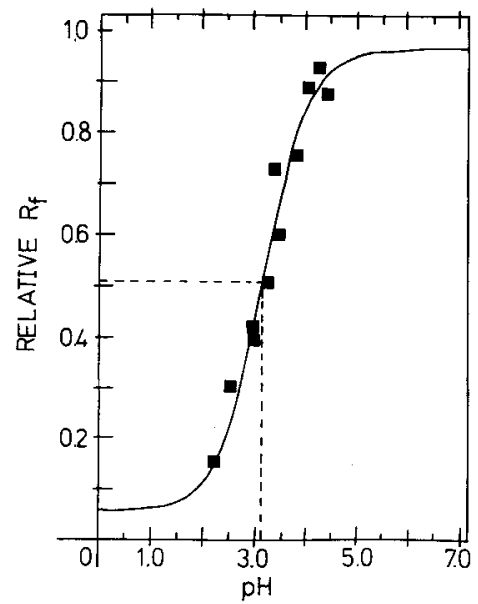

Fig. 3. Determination of the $p \mathrm{~K}$ of $F 1-X$ by its electrophoretic mobility. F1-X was investigated electrophoretically at the $\mathrm{pH}$ values shown, its mobility is given relative to that of FMN, and lumiflavin-3propanesulfonic acid. The curve traced through the points represents the best fit calculated for a single ionisation, and a $\mathrm{pK}$ of 3.1. cf. Materials and Methods for further details
Gas-liquid chromatography and mass spectrophotometric analysis of the methanol- $\mathrm{HCl}$ solvolysis products of $\mathrm{F} 1-\mathrm{X}$ yielded a further important clue on the nature of the substituent. Fig. 4 shows that one low-molecular-weight solvolytic fragment is identical with malonic acid dimethyl ester. It is therefore most likely that malonic acid is either the residue linked to riboflavin or part of it. The first ionisation of malonic acid ( $\mathrm{p} K 2.85$ ) is also in a range compatible to that of F1-X. At this point it was hoped that ${ }^{1} \mathrm{H}-\mathrm{NMR}$ might yield final information needed for the structural attribution. Preliminary ${ }^{1} \mathrm{H}-\mathrm{NMR}$ spectra of purified F1-X were, however, puzzling in that they showed a different signal pattern for the presumed ribityl side chain as compared to riboflavin (Fig. 5) or FMN, however, no further signal. The reason for this will be detailed below.

Comparison of synthetic 5'-malonyl-riboflavin with native F1-X and structural identification

In view of the data and properties discussed above, the chemical synthesis of a riboflavin carrying a malonyl half ester in the ribityl side chain was attempted. The best results were obtained upon incubation of riboflavin with a slight excess of malonic acid in a polar, aprotic solvent, and in the presence of condensing agent such as carbodiimide. A series of products is formed by this method which probably correspond to formation of (mono and poly) half esters at the different hydroxy groups of the ribityl chain. One main component has chromatographic (thin layer, and high pressure, cf. Fig. 1 and Table 1) properties indistinguishable from those of native F1-X.

Hence, this component was purified by ion-exchange chromatography and then by HPLC as detailed in Materials

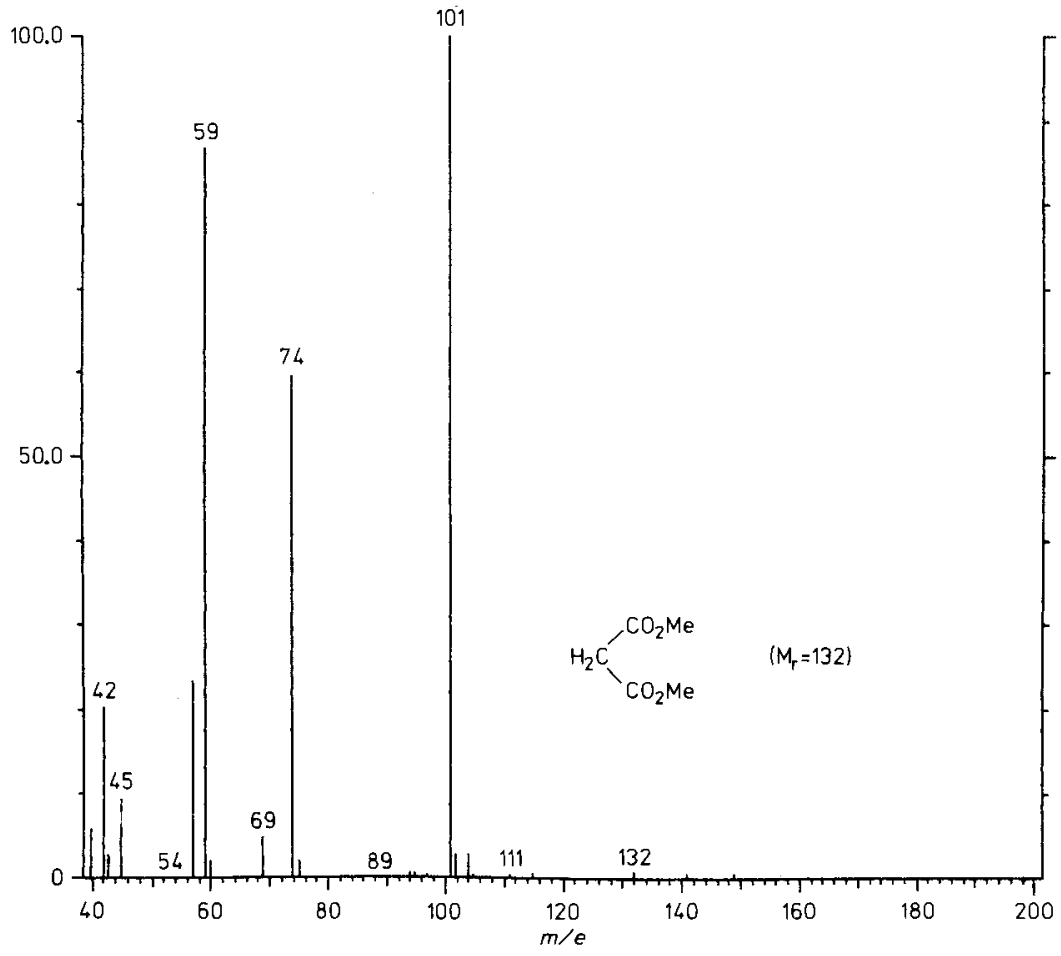

Fig. 4. Mass spectrum obtained after solvolysis and analysis of FI-X by gas chromatography/mass spectrometry. No mass peak could be detected upon direct insertion analysis of F1-X. However, when the compound $(10 \mu \mathrm{g})$ was incubated in $100 \mu \mathrm{l} 0.5 \mathrm{M}$ methanolic $\mathrm{HCl}$ for $30 \mathrm{~min}$, and the product analyzed by gas chromatography/mass spectroscopy the mass spectrum shown was obtained from a major peak eluting at 6 min. Its spectrum is identical to that of dimethylmalonate (cf. structure insert). The control experiment with malonic acid yielded the same retention time and fragmentation pattern 

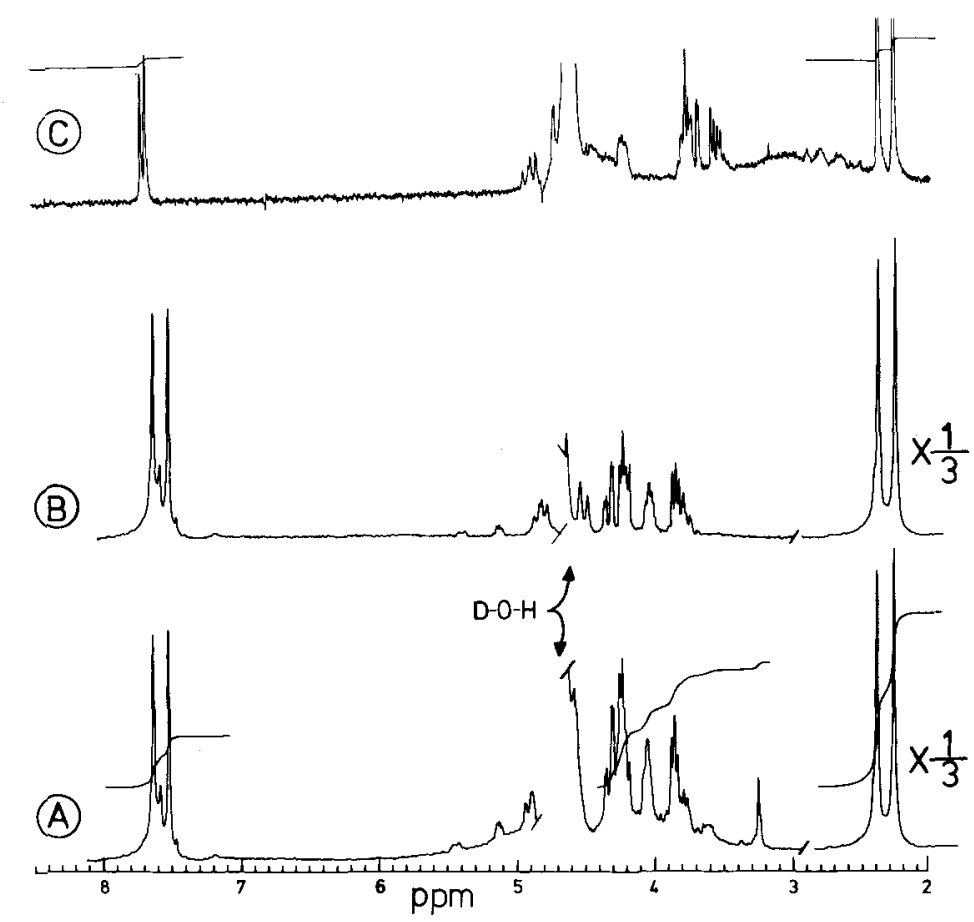

Fig. 5. 250-MHz ${ }^{1} \mathrm{H}-\mathrm{NMR}$ spectrum of native, and synthetic F1-X. Native F1-X, as obtained from HPLC purification, was lyophylised three times with $99.95 \%{ }^{2} \mathrm{H}_{2} \mathrm{O}$, and then measured in the same solvent. Spectrum A was obtained after 1000 scans from a 0.3 -ml sample containing approx. $2 \mu \mathrm{mol} \mathrm{F1-X.} \mathrm{Note} \mathrm{that} \mathrm{the} \mathrm{integration} \mathrm{of} \mathrm{the} \mathrm{signal} \mathrm{at} \mathrm{approx.} 3.25 \mathrm{ppm}$, which is attributed to the malonyl $\alpha$-protons is significantly less than expected for 2 protons. Spectrum B was obtained from $15 \mu \mathrm{mol}$ of synthetic F1-X under the same conditions, however, no particular care was taken to keep the material in the frozen state when dissolved in ${ }^{2} \mathrm{H}_{2} \mathrm{O}$, and prior to measurement. Note that under these circumstances the singlet at $3.25 \mathrm{ppm}$ cannot be observed. Spectrum $C$ was obtained with riboflavin. In spectra $A$ and $B$ in the region of the aromatic protons (two) minor peaks are present in addition to the signals attributed to the flavin C6, and C9 hydrogens (cf. structure insert in Fig. 2). The singlets at 2.26 ppm and $2.40 \mathrm{ppm}$ are those of the $7-\mathrm{CH}_{3}$ and $8-\mathrm{CH}_{3}$ groups of the isoalloxazine moiety. The peaks in the region from $3.6-5.5 \mathrm{ppm}$ are attributed to the ribityl side chain protons. Note the difference in overall shape and resolution in this area between F1-X, and riboflavin, which probably indicates different side-chain mobilities, and conformers. cf. Materials and Methods for further details

and Methods. Unexpectedly, rechromatography (HPLC, RP-18) of purified synthetic material (obtained by collection of the main peak 3 , Fig. 1) at $t=\approx 12.5$ min invariably yielded an elution profile in which the main peak was preceded by a minor peak or shoulder (Fig. 1). Exactly the same behaviour was observed with native F1-X. The ${ }^{1} \mathrm{H}-\mathrm{NMR}$ spectra of native F1-X, and of synthetic material (Fig. 5), are practically identical in that they show the same signal pattern for the 7,8-dimethyl groups at $2.2-2.5 \mathrm{ppm}$, the 6 and 9 protons at $7.5-7.7 \mathrm{ppm}$, as well as for the signals of the side chain from $3.6-5.5 \mathrm{ppm}$. Note that, in contrast to the spectrum of riboflavin, both native and synthetic material show the presence of 'contaminating' peaks in the aromatic region $(7.5-7.7 \mathrm{ppm})$. This finding is assumed to originate in an isomerisation of the ester linkage between the malonyl group and the ribityl side chain. Although no direct proof can be given, comparison with chemical phosphorylation of riboflavin $[17,18]$ suggests that the malonyl group is linked to the sterically least hindered group, i.e. the terminal $5^{\prime}-\mathrm{OH}$. From there a relatively rapid intramolecular migration is conceivable probably leading to the $4^{\prime}$ isomer as shown on Scheme 2.

The independence of the elution profile with respect to incubation time implies that the $t_{1 / 2}$ of the supposed isomerisation process can be relatively fast, at least of the order of the HPLC separation time, and also implies that the observed resolution reflects the thermodynamic distribution of the isomers. From chemical work [16] it is known that esterification occurs primarily at positions $5^{\prime}$ and $4^{\prime}$ in that order and that migrations of substituents between these and also the $3^{\prime}$ and $2^{\prime}$

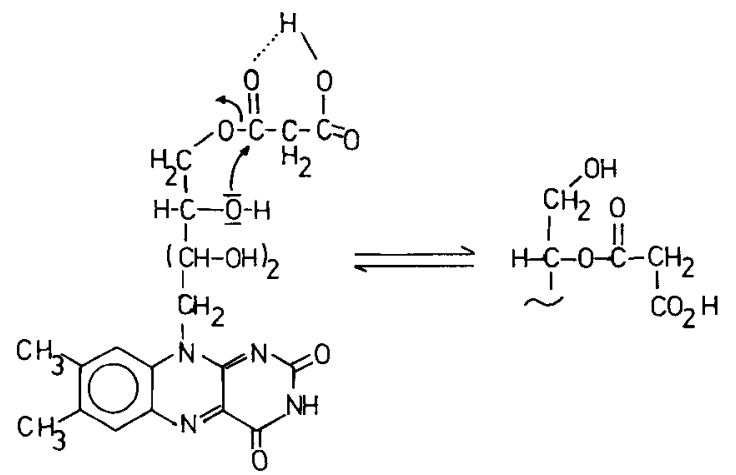

Scheme 2. Isomerisation to the $4^{\prime}$ isomer

positions are not uncommon. In the case of riboflavin phosphates migration and equilibration between all ribityl-OH groups has been demonstrated to occur upon acid catalysis [16-18].

Rapid equilibration is also consistent with the fact that ${ }^{1} \mathrm{H}-\mathrm{NMR}$ spectra originally did not show a signal for the malonyl methylene group. Exchange of these protons during repeated lyophilization/dissolution of the samples of native F1-X in high grade ${ }^{2} \mathrm{H}_{2} \mathrm{O}$ eliminates the signal originally present. When care is taken in order to minimise such a process, a singlet signal at $3.25 \mathrm{ppm}$ can be observed which integrates for two protons and decreases with time (Fig. 6). In view of 


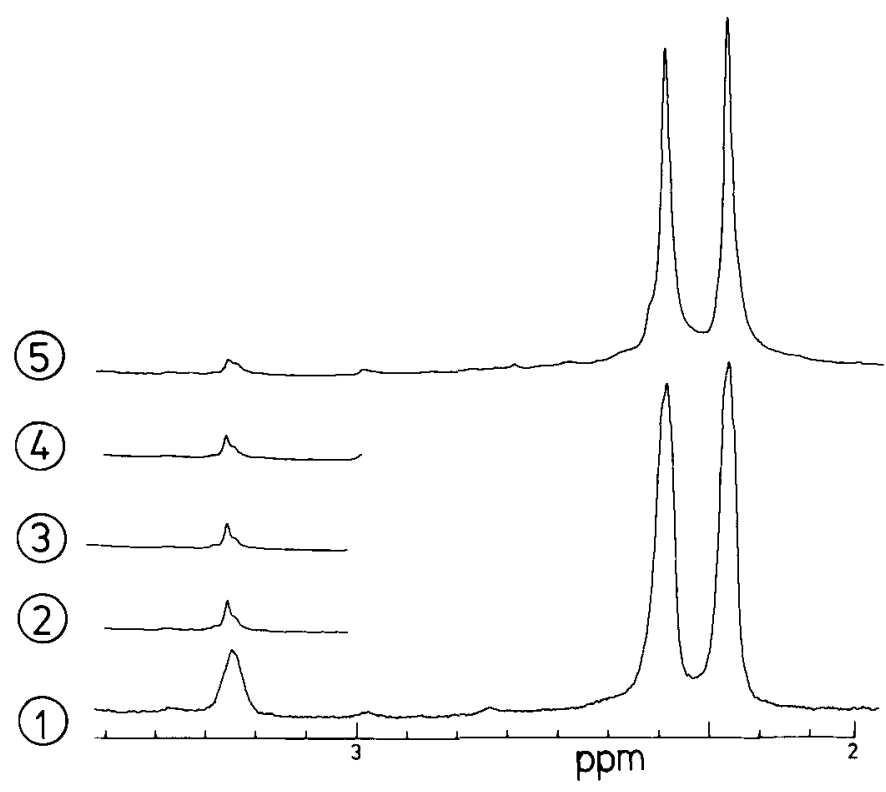

Fig. 6. Time dependence of aliphatic proton NMR spectrum of $F 1-X$. The spectra shown were recorded under the conditions described in Fig. 5 using native F1-X. Curves $1-5$ were obtained at the beginning and then after $2 \mathrm{~h}, 4 \mathrm{~h}, 7 \mathrm{~h}$ and $20 \mathrm{~h}$ respectively. The two singlets at $2.26 \mathrm{ppm}$ and $2.40 \mathrm{ppm}$, are from the $7-\mathrm{CH}_{3}$ and $8-\mathrm{CH}_{3}$ groups and were used as standards. The singlet at $3.25 \mathrm{ppm}$ is that of the malonic half ester moiety $\alpha$-protons, which are shown to exchange with solvent deuterons

their acidity the ease of exchange of methylene protons of malonyl groups is readily understood.

It is reasonable to assume that both in riboflavin and in F1-X the N10 side chain has the same D-ribityl configuration. This follows from the identity of all physical properties tested, and in particular of the NMR pattern of the side chain protons. Identity was also demonstrated directly with Lactobacillus case i in a biological test [7]. After mild acidic hydrolysis of the malonyl group, the hydrolysate of F1-X was found to support growth to the same degree, as authentic vitamin $B_{2}$.

\section{Conclusions}

The present results conclusively establish the chemical structure of F1-X as malonylriboflavin. The position of substitution, although not absolutely proven, is most probably at $5^{\prime}$ of the D-ribityl side chain. Migration of the malonyl function, most likely to position $4^{\prime}$, occurs readily. Its biological significance remains speculative, however.
The ease of hydrolytic and photochemical degradation of $\mathrm{F} 1-\mathrm{X}$ to riboflavin is remarkable and might reflect a physiological function. Particularly the ease of photodecarboxylation of $\mathrm{F} 1-\mathrm{X}$ to riboflavin, which is subject to current investigation, might be related to the triggering-mechanism of phototropism. The interesting chemical and photochemical properties of $5^{\prime}$-malonylriboflavin described in this work are all consistent with its possible role as the long sought after 'blue light' receptor triggering phototropism. In particular it has to be pointed out that F1-X is the major flavin chromophore $(80 \%$ of total flavin [3]) in the early development of the Avena coleoptile. Proof of our hypothesis, however, will only be possible when direct assays of the photoreceptor function are feasible.

This work was supported in its initial part by Sonderforschungsbereich 138 (Deusche Forschungsgemeinschaft); after Prof. Dr P. Hemmerich's death, by a grant from the Deutsche Forschungsgemeinschaft to SG (Gh2 4/4).

\section{REFERENCES}

1. Pohl, U. \& Russo, V. E. (1984) in Membranes and Sensory Transduction (Lenci, F. \& Colombetti, G., eds) pp. 231-329. Plenum Press, New York.

2. Schmidt, W. (1980) Struct. Bonding, 41, 1-44.

3. Zenk, M. H. (1967) Z. Pflanzenphysiol. 56, 122-140.

4. Zenk, M. H. (1967) Z. Pflanzenphysiol. 56, 57-69.

5. Blankenhorn, G., Osuga, D. T., Lee, H. S. \& Feeny, R. E. (1975) Biochim. Biophys. Acta, 386, 470-478.

6. Mayhew, S. G. \& Strating, M. J. (1975) Eur. J. Biochem. 59, $539-$ 544.

7. Official Methods of Analysis for the Association of Official Analytical Chemists (1975) (Horowitz, W., ed.) 12th edn, pp. 816-859, Association of Official Analytical Chemists, Washington, DC.

8. Hemmerich, P. (1964) Helv. Chim. Acta, 47, 464-475.

9. Whitby, L. G. (1951) Biochem. J. 50, 433-438.

10. Ghisla, S., Kenney, W. C., Knappe, W., McIntyre, W. \& Singer, T. P. (1980) Biochemistry, 19, 2537-2544.

11. Ghisla, S. \& Hemmerich, P. (1971) FEBS Lett. 16, 229-232.

12. Ghisla, S., Hartmann, U. \& Hemmerich, P. (1970) Angew. Chem. Int. Ed. Engl. 9, 642-643.

13. Walker, W. H., Singer, T. P., Ghisla, S. \& Hemmerich, P. (1972) Eur. J. Biochem. 26, 279-289.

14. Edmonson, D. E. \& Singer, T. P. (1976) FEBS Lett. 64, 255-265.

15. Walaas, E. \& Walaas, O. (1956) Acta Chem. Scand. 10, 122-133.

16. Suelter, C. H. \& Metzler, D. E. (1960) Biochim. Biophys. Acta, 44, $23-33$.

17. Scola-Nagelschneider, G. \& Hemmerich, P. (1976) Eur. J. Biochem. 66, 567-577.

18. Nielsen, P., Rauschenbach, P. \& Bacher, A. (1983) Anal. Biochem. $130,359-368$.

S. Ghisla, R. Mack, and E. Krienitz, Fakultät für Biologie der Universität Konstanz,

Postfach 5560, D-7750 Konstanz, Federal Republic of Germany

G. Blankenhorn, Efeka Arzneimittelfabrik GmbH \& Co KG,

Postfach 1709, D-3000 Hannover, Federal Republic of Germany

T. Kuster, Medizinisch-Chemische Abteilung, Kinderklinik der Universität Zürich, Steinwegsstrasse 75, CH-8032 Zürich, Switzerland 